\title{
edoc
}

Institutional Repository of the University of Basel

University Library

Schoenbeinstrasse 18-20

CH-4056 Basel, Switzerland

http://edoc.unibas.ch/

\section{Bone and cartilage tissue engineering for facial reconstructive surgery}

Farhadi, J. and Jaquiery, C. and Haug, M. and Pierer, G. and Zeilhofer, H. F. and Martin, I.

Posted at edoc, University of Basel

Official URL: http://edoc.unibas.ch/dok/A5249041

Originally published as:

Farhadi, J. and Jaquiery, C. and Haug, M. and Pierer, G. and Zeilhofer, H. F. and Martin, I.. (2006) Bone and cartilage tissue engineering for facial reconstructive surgery. IEEE engineering in medicine and biology magazine, Vol. 2. S. 106-109.

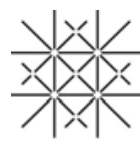


Bone and cartilage tissue engineering in facial reconstructive surgery: clinical need and state of the art

J. Farhadi ${ }^{1,2}$, C. Jaquiery ${ }^{1,2}$, M. Haug $^{1}$, G. Pierer ${ }^{1}$, F. Zeilhofer ${ }^{1}$, M. Heberer², I. Martin ${ }^{2}$

${ }^{1}$ Clinic for Reconstructive Surgery

${ }^{2}$ Institute for Surgical Research and Hospital Management University Hospital Basel, Switzerland

Address correspondence to:

Ivan Martin

Institute for Surgical Research and Hospital Management

University of Basel

Hebelstrasse 20, ZLF, Room 405

4031 Basel, Switzerland

tel: + 4161265 2384; fax: + 41612653990

e-mail: imartin@uhbs.ch 


\begin{abstract}
In facial reconstructive surgery, new techniques based on the principles of tissue engineering have moved over the last decade from the bench closer to the bed side, where they are being combined with the principles of plastic surgery. In particular, mechanically competent cartilage grafts and osteoinductive constructs vascularized by flaps are envisioned to replace autologous or alloplastic materials, with the goal to reduce donor site morbidity and to increase graft durability. Here we provide an overview of typical surgical procedures in facial reconstructive surgery and summarize how advances in cartilage and bone tissue engineering might replace and improve current treatments.
\end{abstract}

Key words: cartilage, bone, tissue engineering, plastic surgery 


\section{Introduction}

Trauma, cancer or congenital abnormalities often lead to cartilaginous and bony defects in the head and neck region. These tissue losses can either be replaced by tissue transfer from a healthy site (autografts) or by non-biological materials (alloplastic implants). Autologous tissue reconstruction is limited by the availability of donor tissue, morbidity at the donor site, time consuming surgery and mismatch of mechanical properties. Alloplastic implants (stainless steel, Dacron, polyacrylates, etc.) are readily available and do not lead to donor site morbidity, but they are not long lasting and are associated with a high rate of complications, such as infection, chronic irritation and sometimes even carcinogenicity. Therefore autologous implants remain the prevalent and also most versatile option in facial reconstructive surgery.

A possible solution for providing sufficient amounts of tissue without the downsides of autologous transplants or alloplastic implants would be to engineer tissues which meet the requirements of the repair site, starting from the patient's own cells. In general, the goals of engineering bone and cartilage in the head and neck area are (i) to achieve similar or even better results as compared to traditional reconstructive techniques and (ii) to avoid the concomitant and sometimes considerable donor site morbidity.

The purpose of this article is to give an overview of some surgical procedures in reconstructive surgery of the head and neck, and describe how Tissue Engineering approaches can replace and improve current treatments.

\section{Clinical need of cartilage}

Cartilage is widely distributed throughout the human body and is comprised of chondrocytes embedded in an extracellular matrix composed primarily of proteoglycans, collagen, and water. Cartilage is a relatively simple but highly specialized connective tissue, which has no internal vascular network and possesses limited ability for repair and regeneration: injury or resection generally results in scar formation, leading to permanent loss of structure and function. Cartilage can be divided into categories according to the 
composition of the matrix and its biological role in the body. Hyaline cartilage, which is rich in type II collagen, can be found in ribs, trachea, nose and articulating surfaces of bones. Elastic cartilage, which contains large amounts of elastin, is found in tissues such as the external ear, the epiglottis, and portions of the larynx. Fibrocartilage, which is rich in type I collagen, can be found as part of the lower and upper lid, menisci, intervertebral disc and in certain ligaments and tendons. Since cartilage nutrition is not from a vascular network, the tissue can be surgically transferred to repair sites with high versatility.

\section{The state of the art of reconstruction}

Shape and function of the nose, ear and eyelid derives from the embedding of hyaline, elastic or fibrocartilage between an epithelial layer and a skin layer. The reconstruction of multilayer defects in these tissues due to trauma, tumor [1] or congenital deformities (e.g., microtia) may be viewed as one of the most technically demanding procedures in facial plastic surgery. Despite past attempts of using alloplastic materials, the use of autologous cartilage, generally harvested from unaffected sites and shaped to the desired form, marks the golden standard for functional or aesthetic recovery.

In reconstruction of multilayer defects of the nasal wall and tip, the combination of various local flaps and autologous cartilage, typically from the nasal septum or the ear, is the basis for high stability, sufficient function and proper three-dimensional shape [2]. Figure 1 illustrates a typical case for the reconstruction of the ala of the nose following tumor resection. After resection of the tumor (Fig 1a), a mucosal flap for innerlining was created (Fig 1b). A septal cartilage graft was harvested, shaped according to the defect (Fig 1c) and secured in the repair site by resorbable sutures (Fig $1 \mathrm{~d}$ ). The entire construct was then covered with a forehead flap and after 4 months resulted in structural and functional reconstruction (Fig. 1e). As an alternative to septal cartilage combined with a local flap, an auricular composite tissue consisting of skin and underlying cartilage can be used for grafting [3;4]. The reconstruction of large defects of the lower or upper lid is similar in concept to the nose reconstruction. The possible donor sites for the cartilage graft are the ear or the nasal 
septum [5]. Different reconstruction concepts are available for the complex three-dimensional structure of the ear, depending on defect size and location [6]. Cartilage grafts are usually required in two or three layer defects located to the helix and anthelix, whereas cartilaginous defects of the concha can be adequately resurfaced with skin flaps if the cartilage framework of the helix and anthelix is preserved. Cartilage donor sites include the ear cartilage itself from the ipsi- or contralateral ear, the nasal septum or rib. In cases of subtotal or total absence of the auricle, complete cartilage framework reconstruction has to be carried out using as much as the cartilaginous part of three ribs [7-9]. Soft tissue coverage is provided by using either local skin or a superficial temporoparietal fascial flap.

\section{Donor site morbidity}

Harvesting cartilage from ear, nasal septum or rib in reconstruction of multilayer defects of the nose, eyelid or ear can lead to several complications. Haematoma, wound infection, skin necrosis, cicatricial deformity but also fulminant chondritis with loss of major parts of ear and septum cartilage or thorax deformity have been described.

\section{Clinical need of bone}

The bone structure in the head

In mammalians, two different principles of bone development have to be considered: the indirect and the direct pathway of bone formation. The indirect or endochondral ossification is based on the differentiation of mesenchymal progenitor cells (MPC) into cartilage, followed by mineralization and replacement of this cartilage by bone matrix produced by osteoblasts. The direct or intramembranous ossification is initiated by clusters of MPC which differentiate directly into metabolically active osteoblasts. During skeletal development, every load bearing long bone is formed by endochondral ossification, whereas intramembranous ossification is responsible for bone formation in the head, including the clavicles.

Due to acting forces in the head and neck area, the facial skeleton is mainly composed of very dense cortical bone. The spongeous part, providing vascularization in long bones, is reduced to a minimum (mandible) or even not existing (malar complex, facial wall of the 
maxillary sinus). As a consequence, the periosteum plays an important role in the vascularization of the facial skeleton [10]. This different type of vascularization, as compared to long bones, favours the incorporation of a non-vascularized, free bone graft, provided sufficient amount of soft tissue in the recipient bed.

\section{The state of the art of reconstruction}

Skeletal defects in the head and neck region arise from trauma, infection, tumor resection or abnormal congenital pathologies. These defects, depending on their size, can either be reconstructed by free bone grafts harvested from the skull [11], the iliac crest or the proximal tibia, or by vascularized tissue grafts using the fibula, scapula and iliac crest [12;13]. The method of free vascularized tissue transfer using microsurgical techniques has become a reliable procedure during the past few years [14]. In case of reconstruction of a whole jaw, bone as well as soft tissue has to be regenerated. The preformation of the vascularized fibular graft, together with simultaneous placement of dental implants, offers an elegant method of immediate prosthetic rehabilitation of the patient, but requires meticulous planning of the operative and reconstructive treatment [15]. The two-stage operating procedure, recently reported [16], is now illustrated in more details in Figure 2. Prior to implant placement during the first stage, the future implant position and the position of the graft are planned on plaster models (Fig. 2a). Utilizing a drilling template with additional gauge (Fig $2 b)$, the implants can be inserted perpendicularly to the surface of the fibular graft providing straight preparation of the drill hole through the bicortical bone. The fibula and the implants are then covered with a split skin graft which has to be isolated against ingrowth of soft tissues by a Gore-Tex ${ }^{\circledR}$ membrane. Six weeks after the first stage procedure, the implants are uncovered and the original drilling template can be applied to perform the planned osteotomies (Fig 2c). After abutment-connection, the bar is fixed to the osteotomized graft and the prostheses attached to the bar construction (Fig 2c). The bar borne prosthesis together with the fibular graft are shaped and fixed to the recipient bed and finally microsurgical connection of the vessels is accomplished. This type of reconstruction allows 
immediate prosthetic rehabilitation after the second operative step (Fig 2d). Alternatively, the vascularized grafts may be harvested from different areas (e.g., iliac crest, scapula), depending on the morphology of the defect and the type of intended reconstruction [17].

\section{Donor site morbidity}

Every harvesting procedure gives rise to donor site morbidity. The morbidity may be limited to postoperative pain but, depending on the amount of bone needed and the harvesting site, wound healing disturbances, chronic pain and even functional impairment can occur. Donor site morbidity can either be analysed subjectively (pain, loss of sensibility) or objectively by assessing clinical or functional parameters (e.g., ankle instability, gait analysis). The iliac crest and the fibula are the most commonly used donor sites in bone regeneration. Donor site morbidity after harvesting bone from the iliac crest is considered low, and severe complications like fractures or large haematoma are rarely observed [18]. Patient perception of morbidity after harvesting a fibular graft is low [19], however complaints like pain, feeling of ankle instability and inability to run are frequently mentioned. Moreover, functional tests revealed gait disturbances as compared to healthy individuals. These findings suggest that, although the morbidity after harvesting a fibular graft is subjectively considered low, the reautomatization of gait may be affected among patients.

\section{Possible applications of osteoconductive materials in the head and neck area}

Osteoconductive materials have been introduced in the reconstructive surgery of bone since many years. Depending on the size and morphology of a given defect, either small granulates or custom-made constructs are needed. Small osteoconductive granulates, alone or in combination with autologous bone chips, can be used in almost every bone regeneration procedure in oral surgery. The additional application of a biodegradable and semipermeable membrane [20] prevents ingrowth of scar tissue and allows locally existing MPC to develop into bone forming osteoblasts (Fig $3 a, b$ ). A very common indication for the use of small granulates is the sinus elevation procedure [21] in order to regenerate bone in the vertical dimension, prior or together with implant placement in the upper jaw (Fig 3c). 
Large defects of the skull, the facial skeleton (Fig 4a) or the jaws have to be regenerated by three dimensional scaffolds which have to fit exactly into a given defect. After performing computed tomography, a three dimensional model of the facial skeleton including the defect can be manufactured (Fig 4b) and finally the scaffold to be used intraoperatively may be produced by rapid prototyping techniques [22]. However, due to the typically large size of the defects, in these cases bone regeneration would require combination of the custom-made osteoconductive scaffold with either osteogenic growth factors or autologous osteoprogenitor cells, in order to generate an osteoinductive graft (see chapter Tissue engineering of bone).

\section{Tissue engineering of cartilage}

The goal of cartilage tissue engineering in facial reconstructive surgery is to generate a graft which can be implanted at different sites of the head and neck by applying the same surgical techniques as in reconstruction using autologous grafts. Engineering of a cartilage graft would start from obtaining a small biopsy from the nasal septum, ear or rib cartilage. This procedure can be performed under local anaesthetic in a minimally invasive fashion, and will not lead to donor site morbidity, as for the harvest of large grafts for reconstructive purposes. After enzymatic digestion of the specimen, the cells would be expanded in vitro and then induced to grow on bioactive degradable scaffolds that provide the structural and biochemical cues to guide their differentiation and generate a three-dimensional (3D) tissue. Such construct would then be transplanted into the defect, where further cell differentiation and tissue integration is expected to occur (Fig 5).

\section{$\underline{\text { Cell sources }}$}

External ear [23;24] and nasal [25-27] chondrocytes have been used with various degrees of success to engineer in vitro and/or in vivo 3D cartilaginous tissues. Taking both cell yields and proliferation rates into account, we recently reported that a biopsy of human ear, nasal or rib cartilage and weighing a few milligrams, would yield tens of millions of cells over a 2-3 week period [28]. This number of cells, based on reported seeding densities of 
non-articular chondrocytes into various 3D scaffolds [23;29], would be sufficient for the generation of autologous grafts of clinically relevant size (i.e., greater than $1 \mathrm{~cm}^{2}$ in size). But the key point is the chondrogenic capacity of these cells, as chondrocytes during monolayer expansion de-differentiate to a fibroblastic stage. Although in principle re-differentiation can be achieved upon transfer into a 3D culture environment [30], the potential of human expanded chondrocytes to re-differentiate and generate a functional matrix is limited [31] and decreases with donor age [32]. To overcome these limitations, specific regulatory molecules (e.g., growth factors, hormones, metabolites) have been employed as medium supplements during the different culture phases. Results indicate that expansion of chondrocytes in the presence of growth factors not only increases the cell proliferation rate, but also maintains the ability of the cells to re-differentiate upon transfer into a $3 D$ environment $[33 ; 34]$ and to subsequently respond to differentiating agents [35]. At present, however, in literature we could not find a comparative animal or clinical study concerning the use of chondrocytes expanded under conditions favouring cell proliferation and maintenance of chondrogenic ability.

An alternative to the use of differentiated chondrocytes is the use of cells with chondrogenic differentiation capacity, like mesenchymal progenitor cells (MPC). MPC can be isolated for instance from bone marrow aspirates and have the potential to differentiate into various mesenchymal tissue lineages [36]. Despite the reports that MPC can generate cartilaginous tissues [37;38], the molecules expressed indicate possible instability of the cartilage phenotype, associated with remodelling of the engineered cartilage into a mineralized tissue. Moreover, no report has been published so far regarding the pre-clinical or clinical use of MPC in facial cartilage reconstruction.

\section{$\underline{\text { Three-dimensional scaffolds }}$}

Another critical element in engineering cartilage is a suitable scaffold that displays biological and physical properties matching both the needs of differentiating chondrocytes in vitro and of regenerating cartilage in vivo [39]. The scaffold must provide sufficient mechanical 
strength and stiffness to substitute initially for wound contraction forces, and later for the remodelling of the tissue. Furthermore, it should enhance cell attachment and provide enough space to allow the exchange of nutrients and waste products and the deposition of extracellular matrix. In addition, the mechanical characteristics of the scaffold should be such, that at the time of implantation the cell-scaffold construct can sustain the surgical manipulation and the insertion of sutures.

Different research groups have used a wide variety of scaffolds in the attempt to generate cartilaginous tissues in vitro. The form and composition of these scaffolds range from nonwoven meshes and foams of alpha-hydroxypolyesters [37;40;41], polyglactin [42] or hyaluronan alkyl esters $[43 ; 44]$ to photo-crosslinked hydrogels $[45 ; 46]$ and sponges based on different types of collagen and glycosaminoglycans [47;48]. Composites consisting of a 3D porous scaffold filled with cells embedded in a fibrin or alginate gel have also been explored. But many of these scaffolds are still in the experimental evaluation and several issues still have to be addressed, related to the interactions between cells and specific substrates, the influence of the pore size distribution on cell behaviour and the effect of scaffold geometry (i.e., in the form of a foam, mesh or gel) on the induction/maintenance of the chondrocytic phenotype.

\section{Upscaling of the constructs}

One of the major challenges in cartilage tissue engineering is the generation of uniform tissues of clinically relevant size (i.e., a few square centimeters in area and 3-4 mm in thickness). An upscaling of the constructs could be reached by the use of bioreactors, where cell seeding and culture may be facilitated by the application of mechanical and/or hydrodynamic forces [49]. Bioreactors would also provide a controlled in vitro environment over specific biochemical and physical signals, which have the potential to regulate chondrogenesis and improve the structure and function of the resulting cartilage tissues [5054]. Despite the great efforts currently dedicated to the development and use of bioreactors for the engineering of functional cartilage tissue, it is still rather unclear which specific physical stimulation regime is required to induce a specific effect on cultured chondrocytes. 


\section{Tissue engineering of bone}

The goal of bone tissue engineering in facial reconstructive surgery is to generate an osteoinductive graft, namely a construct which upon implantation in the area to be reconstructed is capable to initiate the formation of bone tissue. Engineering of an osteoinductive graft of predefined size and shape can be achieved by loading a 3D scaffold with either osteogenic cells or bone morphogenetic proteins. According to the former approach, osteogenic cells are obtained from biopsies of diverse possible tissues (e.g., bone marrow, periosteum) and are typically expanded in culture. The latter approach appears more simple, since it does not require ex vivo cell processing, but opens the biological question of how the overdose of one single molecule could recapitulate the complex set of molecular events physiologically involved in the safe and stable formation of bone tissue.

\section{$\underline{\text { Cell sources }}$}

It has been demonstrated that the regeneration of critically sized long bone defects in a sheep model can be improved by combining osteogenic cells and a ceramic scaffold, whereas the ceramic scaffold alone does not lead to uniform ossification [55]. This study supports the necessity of delivering viable osteogenic cells within a ceramic scaffold in order to achieve a stable and load-bearing osseous formation and integration. MPC isolated from the bone marrow are the most popular cell source to be seeded on a ceramic carrier. Implanted ectopically in subcutaneous pockets of nude mice, they induce bone formation starting from the ceramic surface [56]. Harvesting of bone marrow has to be performed under sterile conditions and the amount of MPC which can be isolated is age-dependent and limited [57]. Considering these drawbacks, attempts have been made to isolate MPC from alternative tissues. Dragoo et al. isolated human MPC from fat tissue and from bone marrow aspirates and compared the osteogenic potential of both cell sources when transfected with adenovirus containing BMP-2 [58]. Fat tissue-derived transfected MPC showed faster osteogenic differentiation as compared with MPC extracted from bone marrow. The 
periosteum from the jaws can easily be harvested under local anesthesia and in an outpatient environment. Schantz and associates demonstrated in vitro osteogenic differentiation of periosteum derived osteoprogenitor cells and ectopic in vivo bone formation using a nude mouse model [59]. Recently, Schimming and Schmelzeisen reported the clinical use of periosteal cells in combination with a polymer fleece in the context of the maxillary sinus elevation procedure [60]. In a series of 27 patients, 18 showed bone formation 6 months after operation. However, it remains unclear whether the detected bone was formed by periosteal cells or by the cells surrounding the defect.

\section{$\underline{\text { Three-dimensional scaffolds }}$}

Support of bone regeneration by osteoconductive materials is a procedure which has been used in surgery for decades to restore parts of the facial skeleton. Due to excellent vascularization of the head and neck, incorporation of these materials in general is uneventful and the potential risk of infection is low as compared to other sites of the body. Osteoconductive materials are biomaterials which support adhesion, proliferation and differentiation of osteogenic cells from surrounding tissues, ultimately leading to bone tissue formation [61]. After an ideal time frame of a few months, the scaffold should be replaced by newly formed bone, undergoing subsequent integration and remodelling. Apart from animal or human bone-derived scaffolds, two main groups of synthetically manufactured osteoconductive materials can be identified: the ceramics and the synthetic polymers. The main differences between these materials are their ability to induce differentiation of cells, their rate of resorption and the possibility to apply rapid prototyping techniques in order to fully control the architecture and the outer design of the scaffold. Ceramics are well known to induce differentiation of potentially osteogenic cells towards the osteogenic lineage [62-67] and they are able to bridge large bony defects in human if combined with MPC [68]. Even if it seems to be possible to design a standardized hydroxyapatite ceramic scaffold with the help of rapid prototyping techniques [69], the architecture of a given scaffold (i.e., the size and the interconnectivity of the pores) as well as the mechanical properties can be controlled much 
better using synthetic polymers [70]. The ability of synthetic polymers to induce osteogenic cell differentiation is on the other hand generally lower than that of ceramics, unless growth factors are incorporated and released in a controlled fashion [71].

\section{Growth factors}

Urist first popularized the concept of a bone-generating protein in 1965 when he made the discovery of bone morphogenetic proteins (BMP) [72]. The BMP family includes the most commonly used molecules for musculoskeletal tissue regeneration applications.

In principle, three different concepts for the use of growth factors are envisioned in bone tissue engineering: (i) A specific growth factor can be applied during culture of osteogenic cells, to enhance proliferation and/or to differentiate cells [73]. After expansion, these cells can be combined with an osteoconductive scaffold to generate an osteoinductive graft. (ii) The desired growth factor may be injected directly at the site together with an osteoconductive material, aiming at recruitment and differentiation of MPC localised in the neighbouring original bone or muscle tissue [74]. (iii) Specific growth factors could also be incorporated within a polymer scaffold which, by degradation, will release the factor with defined kinetics [75].

\section{$\underline{\text { Vascularization and integration }}$}

Due to excellent vascularization of the head and neck area, even large segmental defects of the jaws can be reconstructed by the use of free non vascularized bone grafts [76]. This favourable situation would also allow the use of large engineered grafts for the reconstruction of jaws, minimizing the potential risk of failing integration. In case of insufficient vascularization of the recipient bed, the formation of new blood vessels bringing nutrients to the engineered graft could be promoted by (i) the delivery of angiogenic factors, (ii) the generation of artificial micro-vascular networks, or (iii) the prefabrication of flaps. The use of angiogenic factors is gaining increasing attention by the scientific community, but requires definition and control of appropriate timing and dose of the specific factors. Indeed, it has been recently demonstrated that a long-term continuous delivery of Vascular Endothelial 
Growth Factor (VEGF) by transfected myoblasts leads to normal vascularization, whereas myoblasts with high expression of VEGF induce hemangiomas [77]. The generation of microvascular networks by the insertion of a vascular pedicle into the engineered tissue, buried subcutaneously, is an interesting innovative strategy, which is currently being explored in a variety of models [78;79]. The prefabrication of a flap in combination with engineered osteoinductive grafts has been recently described for the reconstruction of an almost entire lower jaw using bovine bone-derived ceramic, BMP-2 and MPC harvested from the bone marrow [80]. After designing the jaw with the help of 3D imaging, these components were implanted subcutaneously in the back of the patient and 6 weeks later the graft was transferred microsurgically together with the latissimus dorsi muscle. At a first glance it seems appealing to transfer the engineered graft together with an excellent vascularized muscle. However, taken into account that the harvesting procedure of the latissimus dorsi muscle may cause considerable donor site morbidity, the advantages of the above described procedure are questionable.

In the head and neck area, stable osteosynthesis allows free vascularized bone grafts as well as engineered grafts to integrate under unloaded conditions. Despite stable and load bearing osteosynthesis in the mandible, the bony integration of an engineered graft of the lower jaw may require more time as compared to other unloaded bony structures of the head [81]. Due to pattern-dependent functional deformation of the mandible during mandibular movements, interfragmentary motion may occur between the original jaw and the graft, which may prevent efficient and rapid integration of the graft.

\section{Advances for clinical application and future horizons}

In this paper we have reviewed some of the techniques that are being developed to manipulate human chondrocytes and MPC to generate cartilaginous and osteoinductive tissues. Considering that engineered cartilage and bone tissues in reconstructive surgery of the head and neck would have to restore form and function, the main challenges in the future will be related to improve methods allowing to define the shape and stage of development of 
the engineered tissues. Moreover, since the clinical use of engineered tissues in facial reconstructive surgery is so far anecdotal, critical will also be to identify which surgical procedures will first benefit from the advances in tissue engineering.

Cartilage grafts for nasal reconstructive surgery will be probably the first application in the clinics, as these grafts have to be fairly small and after implantation would be embedded in a well vascularized bed. Furthermore, the nose is not subjected to high mechanical stresses directly after implantation of a graft and therefore the graft has to have only a certain amount of structural support, but does not need to be fully stable. Similar considerations are valid for reconstruction of the eyelids. Instead, the clinical use of engineered ear cartilage grafts is expected to be more complex, as in most clinical situations there is the need to reconstruct a soft tissue defect next to the cartilage defect. Furthermore, ear cartilage has a more complex anatomical shape, and the engineered ear cartilage may need to be created by computer-aided designed templates. An important issue for the clinical use of engineered cartilage in facial and reconstructive surgery will be to identify the structural and functional properties of the tissue engineered grafts, which need to be matched for the efficacy and safety of the implantation.

The reconstruction of bone defects in the head and neck region by engineered grafts is already close to clinical applications. One of the main problems in bone tissue engineering is to induce rapid vascularization when a certain size of the constructs is reached. As the engineering of a vascular tissue is not yet achievable, the combination of tissue engineering techniques with flap surgery could bridge this gap and lead to the clinical application of engineered bone in facial reconstruction. Furthermore, imaging techniques combined with computational modeling and fabrication of scaffolds through rapid prototyping techniques are likely to play an important role, as the facial bones have complex 3D structures.

One major challenge for the routine clinical use of engineered tissues is related to the manufacturing process, which at present is costly, impractical and not sufficiently standardized. In this context, we envision that 3D tissues could be engineered within closed bioreactor units, with advanced control systems which would facilitate streamlining and 
automation of the numerous labor-intensive steps. Starting from a patient's tissue biopsy, a bioreactor system could isolate, expand, seed on a scaffold, and differentiate specific cell types, thereby performing the different processing phases within a single closed and automated system. Such bioreactor would enable competent hospitals and clinics to carry out autologous tissue engineering for their own patients, eliminating logistical issues of transferring specimens between locations. This would also eliminate the need for large and expensive GMP tissue engineering facilities and minimize operator handling, with the final result of reducing the cost of tissue engineered products for the Health System and for the community. Altogether, when efficiently designed for low-cost operation, novel bioreactor systems could thus facilitate spreading novel and powerful cell-based tissue engineering approaches, which would otherwise remain confined within the context of academic studies or restricted to elite social classes or systems [49]. 


\section{Figure Legends}

\section{Figure 1}

State of the art surgical reconstruction of the ala of the nose. a) Defect after tumor resection. b) Mucosal flap for innerlining. c) Harvested autologous graft from septal cartilage. d) Graft fixed in place. e) Result 4 months after reconstruction.

\section{Figure 2}

Reconstruction of a whole upper jaw by preformed fibular graft. a) Reconstruction plan on a plaster model, customized gauge in titanium, prepared for the first stage procedure. b) Drilling template used during the second stage procedure to perform the planned osteotomies. c) Osteotomized fibular graft, with bar reconstruction fixed on already osseointegrated dental implants. d) Transferred fibular graft fixed to the facial skeleton by miniplates, immediately after the second stage procedure.

\section{Figure 3}

Use of autologous bone chips and osteoconductive material in maxillofacial bone regeneration procedures. a) Split crest of upper jaw with simultaneous placement of dental implants, and remaining gaps filled with autologous bone chips. b) Regenerated area covered with a semipermeable membrane. c) Sinus elevation procedure together with simultaneous placement of a single implant; indicated are the mobilized and elevated sinus membrane (long arrow), and the newly formed space filled with osteoconductive material (short arrow) 


\section{Figure 4}

Severe defect of right anterior skull and malar complex. a) Three dimensional CT scan. b) Stereolithographic three-dimensional model of the facial skeleton, showing the complex defect and used to define the shape of the needed graft.

\section{Figure 5.}

Phases involved in an envisioned procedure of engineered cartilage for reconstruction of the ala of the nose. a) A smal biopsy in the nasal septum is harvested and used to isolate and expand autologous chondrocytes. b) Cells are then seeded into a scaffold to generate a tissue of predefined size and shape, which after implantation would further develop, remodel and integrate with surrounding tissues. 


\section{References}

1 Lee, D., Nash, M., and Har-El, G., "Regional spread of auricular and periauricular cutaneous malignancies," Laryngoscope, vol. 106, no. 8, pp. 998-1001, Aug.1996.

2 Burget, G. C. and Menick, F. J., "Nasal support and lining: the marriage of beauty and blood supply," Plast.Reconstr.Surg., vol. 84, no. 2, pp. 189-202, Aug.1989.

3 Frank R. Defectus marginis alae nasi. Jarb Wein KK Krankenanst 5, 258-263. 1896.

4 Gillies H. New free graft (of skin and ear cartilage) applied to reconstruction of the nostril. Br.J.Surg. 30, 305-307. 1943.

5 Baylis, H. I., Perman, K. I., Fett, D. R., and Sutcliffe, R. T., "Autogenous auricular cartilage grafting for lower eyelid retraction," Ophthal.Plast.Reconstr.Surg., vol. 1, no. 1, pp. 23-27, 1985.

6 Haug, M., Schoeller, T., Wechselberger, G., Otto, A., and Piza-Katzer, H., "[External ear injuries--classification and therapeutic concept]," Unfallchirurg, vol. 104, no. 11, pp. 1068-1075, Nov.2001.

7 Brent, B., "The correction of mi-rotia with autogenous cartilage grafts: I. The classic deformity.?," Plast.Reconstr.Surg., vol. 66, no. 1, pp. 1-12, July1980.

8 Firmin, F., "Ear reconstruction in cases of typical microtia. Personal experience based on 352 microtic ear corrections," Scand.J.Plast.Reconstr.Surg.Hand Surg., vol. 32, no. 1, pp. 35-47, Mar.1998.

9 Nagata, S., "A new method of total reconstruction of the auricle for microtia," Plast.Reconstr.Surg., vol. 92, no. 2, pp. 187-201, Aug.1993.

10 Beckers, H., "[The significance of the periosteum for the growth and vascularization of the tooth-bearing mandible]," Dtsch.Z.Mund Kiefer Gesichtschir., vol. 11, no. 3, pp. 195207, May1987. 
11 lizuka, T., Smolka, W., Hallermann, W., and Mericske-Stern, R., "Extensive augmentation of the alveolar ridge using autogenous calvarial split bone grafts for dental rehabilitation," Clin.Oral Implants.Res., vol. 15, no. 5, pp. 607-615, Oct.2004.

12 Schmelzeisen, R., Hausamen, J. E., Neukam, F. W., and Schliephake, H., "[Microsurgical reanastomosis of scapula transplants for maxillofacial bone reconstruction]," Fortschr.Kiefer Gesichtschir., vol. 39 pp. 67-70, 1994.

13 Cordeiro, P. G., Disa, J. J., Hidalgo, D. A., and Hu, Q. Y., "Reconstruction of the mandible with osseous free flaps: a 10-year experience with 150 consecutive patients," Plast.Reconstr.Surg., vol. 104, no. 5, pp. 1314-1320, Oct.1999.

14 Yim, K. K. and Wei, F. C., "Fibula osteoseptocutaneous flap for mandible reconstruction," Microsurgery, vol. 15, no. 4, pp. 245-249, 1994.

15 Rohner, D., Kunz, C., Bucher, P., Hammer, B., and Prein, J., "[New possibilities for reconstructing extensive jaw defects with prefabricated microvascular fibula transplants and ITI implants]," Mund Kiefer Gesichtschir., vol. 4, no. 6, pp. 365-372, Nov.2000.

16 Jaquiery, C., Rohner, D., Kunz, C., Bucher, P., Peters, F., Schenk, R. K., and Hammer, B., "Reconstruction of maxillary and mandibular defects using prefabricated microvascular fibular grafts and osseointegrated dental implants - a prospective study," Clin.Oral Implants.Res., vol. 15, no. 5, pp. 598-606, Oct.2004.

17 Holle, J., Vinzenz, K., Wuringer, E., Kulenkampff, K. J., and Saidi, M., "The prefabricated combined scapula flap for bony and soft-tissue reconstruction in maxillofacial defects--a new method," Plast.Reconstr.Surg., vol. 98, no. 3, pp. 542-552, Sept.1996.

18 Niedhart, C., Pingsmann, A., Jurgens, C., Marr, A., Blatt, R., and Niethard, F. U., "[Complications after harvesting of autologous bone from the ventral and dorsal iliac crest - a prospective, controlled study]," Z.Orthop.Ihre Grenzgeb., vol. 141, no. 4, pp. 481-486, July2003. 
19 Bodde, E. W., de Visser, E., Duysens, J. E., and Hartman, E. H., "Donor-site morbidity after free vascularized autogenous fibular transfer: subjective and quantitative analyses," Plast.Reconstr.Surg., vol. 111, no. 7, pp. 2237-2242, June2003.

20 Buser, D., Dula, K., Lang, N. P., and Nyman, S., "Long-term stability of osseointegrated implants in bone regenerated with the membrane technique. 5-year results of a prospective study with 12 implants," Clin.Oral Implants.Res., vol. 7, no. 2, pp. 175-183, June1996.

21 Simion, M., Fontana, F., Rasperini, G., and Maiorana, C., "Long-term evaluation of osseointegrated implants placed in sites augmented with sinus floor elevation associated with vertical ridge augmentation: a retrospective study of 38 consecutive implants with 1- to 7-year follow-up," Int.J.Periodontics.Restorative.Dent., vol. 24, no. 3, pp. 208-221, June2004.

22 Wagner, J. D., Baack, B., Brown, G. A., and Kelly, J., "Rapid 3-dimensional prototyping for surgical repair of maxillofacial fractures: a technical note," J.Oral Maxillofac.Surg., vol. 62 , no. 7 , pp. 898-901, July2004.

23 Rodriguez, A., Cao, Y. L., Ibarra, C., Pap, S., Vacanti, M., Eavey, R. D., and Vacanti, C. A., "Characteristics of cartilage engineered from human pediatric auricular cartilage," Plast.Reconstr.Surg., vol. 103, no. 4, pp. 1111-1119, Apr.1999.

24 van Osch, G. J., van der Veen, S. W., and Verwoerd-Verhoef, H. L., "In vitro redifferentiation of culture-expanded rabbit and human auricular chondrocytes for cartilage reconstruction," Plast.Reconstr.Surg., vol. 107, no. 2, pp. 433-440, Feb.2001.

25 van Osch, G. J., Marijnissen, W. J., van der Veen, S. W., and Verwoerd-Verhoef, H. L., "The potency of culture-expanded nasal septum chondrocytes for tissue engineering of cartilage," Am.J.Rhinol., vol. 15, no. 3, pp. 187-192, May2001.

26 Rotter, N., Bonassar, L. J., Tobias, G., Lebl, M., Roy, A. K., and Vacanti, C. A., "Age dependence of cellular properties of human septal cartilage: implications for tissue engineering," Arch.Otolaryngol.Head Neck Surg., vol. 127, no. 10, pp. 1248-1252, Oct.2001. 
27 Kafienah, W., Jakob, M., Demarteau, O., Frazer, A., Barker, M. D., Martin, I., and Hollander, A. P., "Three-dimensional tissue engineering of hyaline cartilage: comparison of adult nasal and articular chondrocytes," Tissue Eng, vol. 8, no. 5, pp. 817-826, Oct.2002.

28 Tay, A. G., Farhadi, J., Suetterlin, R., Pierer, G., Heberer, M., and Martin, I., "Cell yield, proliferation, and postexpansion differentiation capacity of human ear, nasal, and rib chondrocytes," Tissue Eng, vol. 10, no. 5-6, pp. 762-770, May2004.

29 Rotter, N., Tobias, G., Lebl, M., Roy, A. K., Hansen, M. C., Vacanti, C. A., and Bonassar, L. J., "Age-related changes in the composition and mechanical properties of human nasal cartilage," Arch.Biochem.Biophys., vol. 403, no. 1, pp. 132-140, July2002.

30 Benya, P. D. and Shaffer, J. D., "Dedifferentiated chondrocytes reexpress the differentiated collagen phenotype when cultured in agarose gels," Cell, vol. 30, no. 1, pp. 215-224, Aug.1982.

31 Bonaventure, J., Kadhom, N., Cohen-Solal, L., Ng, K. H., Bourguignon, J., Lasselin, C., and Freisinger, P., "Reexpression of cartilage-specific genes by dedifferentiated human articular chondrocytes cultured in alginate beads," Exp.Cell Res., vol. 212, no. 1, pp. 97-104, May1994.

32 Bradham, D. M. and Horton, W. E., Jr., "In vivo cartilage formation from growth factor modulated articular chondrocytes," Clin.Orthop., no. 352, pp. 239-249, July1998.

33 Martin, I., Vunjak-Novakovic, G., Yang, J., Langer, R., and Freed, L. E., "Mammalian chondrocytes expanded in the presence of fibroblast growth factor 2 maintain the ability to differentiate and regenerate three-dimensional cartilaginous tissue," Exp.Cell Res., vol. 253, no. 2, pp. 681-688, Dec.1999.

34 Jakob, M., Demarteau, O., Schafer, D., Hintermann, B., Dick, W., Heberer, M., and Martin, I., "Specific growth factors during the expansion and redifferentiation of adult human articular chondrocytes enhance chondrogenesis and cartilaginous tissue formation in vitro," J.Cell Biochem., vol. 81, no. 2, pp. 368-377, Mar.2001. 
35 Martin, I., Suetterlin, R., Baschong, W., Heberer, M., Vunjak-Novakovic, G., and Freed, L. E., "Enhanced cartilage tissue engineering by sequential exposure of chondrocytes to FGF-2 during 2D expansion and BMP-2 during 3D cultivation," J.Cell Biochem., vol. 83, no. 1, pp. 121-128, June2001.

36 Prockop, D. J., "Marrow stromal cells as stem cells for nonhematopoietic tissues," Science, vol. 276, no. 5309, pp. 71-74, Apr.1997.

37 Martin, I., Shastri, V. P., Padera, R. F., Yang, J., Mackay, A. J., Langer, R., VunjakNovakovic, G., and Freed, L. E., "Selective differentiation of mammalian bone marrow stromal cells cultured on three-dimensional polymer foams," J.Biomed.Mater.Res., vol. 55, no. 2, pp. 229-235, May2001.

38 Johnstone, B., Hering, T. M., Caplan, A. I., Goldberg, V. M., and Yoo, J. U., "In vitro chondrogenesis of bone marrow-derived mesenchymal progenitor cells," Exp.Cell Res., vol. 238 , no. 1 , pp. 265-272, Jan.1998.

39 LeBaron, R. G. and Athanasiou, K. A., "Ex vivo synthesis of articular cartilage," Biomaterials, vol. 21, no. 24, pp. 2575-2587, Dec.2000.

40 Shastri, V. P., Martin, I., and Langer, R., "Macroporous polymer foams by hydrocarbon templating," Proc.Natl.Acad.Sci.U.S.A, vol. 97, no. 5, pp. 1970-1975, Feb.2000.

41 Freed, L. E., Marquis, J. C., Nohria, A., Emmanual, J., Mikos, A. G., and Langer, R., "Neocartilage formation in vitro and in vivo using cells cultured on synthetic biodegradable polymers," J.Biomed.Mater.Res., vol. 27, no. 1, pp. 11-23, Jan.1993.

42 Marijnissen, W. J., van Osch, G. J., Aigner, J., van der Veen, S. W., Hollander, A. P., Verwoerd-Verhoef, H. L., and Verhaar, J. A., "Alginate as a chondrocyte-delivery substance in combination with a non-woven scaffold for cartilage tissue engineering," Biomaterials, vol. 23, no. 6, pp. 1511-1517, Mar.2002.

43 Campoccia, D., Doherty, P., Radice, M., Brun, P., Abatangelo, G., and Williams, D. F., "Semisynthetic resorbable materials from hyaluronan esterification," Biomaterials, vol. 19, no. 23, pp. 2101-2127, Dec.1998. 
44 Grigolo, B., Lisignoli, G., Piacentini, A., Fiorini, M., Gobbi, P., Mazzotti, G., Duca, M., Pavesio, A., and Facchini, A., "Evidence for redifferentiation of human chondrocytes grown on a hyaluronan-based biomaterial (HYAff 11): molecular, immunohistochemical and ultrastructural analysis," Biomaterials, vol. 23, no. 4, pp. 1187-1195, Feb.2002.

45 Elisseeff, J., McIntosh, W., Fu, K., Blunk, B. T., and Langer, R., "Controlled-release of IGF-I and TGF-beta1 in a photopolymerizing hydrogel for cartilage tissue engineering," J.Orthop.Res., vol. 19, no. 6, pp. 1098-1104, Nov.2001.

46 Bryant, S. J. and Anseth, K. S., "Hydrogel properties influence ECM production by chondrocytes photoencapsulated in poly(ethylene glycol) hydrogels," J.Biomed.Mater.Res., vol. 59, no. 1, pp. 63-72, Jan.2002.

47 Nehrer, S., Breinan, H. A., Ramappa, A., Shortkroff, S., Young, G., Minas, T., Sledge, C. B., Yannas, I. V., and Spector, M., "Canine chondrocytes seeded in type I and type II collagen implants investigated in vitro," J.Biomed.Mater.Res., vol. 38, no. 2, pp. 95-104, 1997.

48 Lee, C. R., Breinan, H. A., Nehrer, S., and Spector, M., "Articular cartilage chondrocytes in type I and type II collagen-GAG matrices exhibit contractile behavior in vitro," Tissue Eng, vol. 6, no. 5, pp. 555-565, Oct.2000.

49 Martin, I., Wendt, D., and Heberer, M., "The role of bioreactors in tissue engineering," Trends Biotechnol., vol. 22, no. 2, pp. 80-86, Feb.2004.

50 Demarteau, O., Jakob, M., Schafer, D., Heberer, M., and Martin, I., "Development and validation of a bioreactor for physical stimulation of engineered cartilage," Biorheology, vol. 40, no. 1-3, pp. 331-336, 2003.

51 Wendt, D., Marsano, A., Jakob, M., Heberer, M., and Martin, I., "Oscillating perfusion of cell suspensions through three-dimensional scaffolds enhances cell seeding efficiency and uniformity," Biotechnol.Bioeng., vol. 84, no. 2, pp. 205-214, Oct.2003.

52 Freed, L. E. and Vunjak-Novakovic, G., "Spaceflight bioreactor studies of cells and tissues," Adv.Space Biol.Med., vol. 8 pp. 177-195, 2002. 
53 Demarteau, O., Wendt, D., Braccini, A., Jakob, M., Schafer, D., Heberer, M., and Martin, I., "Dynamic compression of cartilage constructs engineered from expanded human articular chondrocytes," Biochem.Biophys.Res.Commun., vol. 310, no. 2, pp. 580-588, Oct.2003.

54 Martin, I., Obradovic, B., Treppo, S., Grodzinsky, A. J., Langer, R., Freed, L. E., and Vunjak-Novakovic, G., "Modulation of the mechanical properties of tissue engineered cartilage," Biorheology, vol. 37, no. 1-2, pp. 141-147, 2000.

55 Kon, E., Muraglia, A., Corsi, A., Bianco, P., Marcacci, M., Martin, I., Boyde, A., Ruspantini, I., Chistolini, P., Rocca, M., Giardino, R., Cancedda, R., and Quarto, R., "Autologous bone marrow stromal cells loaded onto porous hydroxyapatite ceramic accelerate bone repair in critical-size defects of sheep long bones," J.Biomed.Mater.Res., vol. 49, no. 3, pp. 328-337, Mar.2000.

56 Haynesworth, S. E., Goshima, J., Goldberg, V. M., and Caplan, A. I., "Characterization of cells with osteogenic potential from human marrow," Bone, vol. 13, no. 1, pp. 81-88, 1992.

57 Phinney, D. G., Kopen, G., Righter, W., Webster, S., Tremain, N., and Prockop, D. J., "Donor variation in the growth properties and osteogenic potential of human marrow stromal cells," J.Cell Biochem., vol. 75, no. 3, pp. 424-436, Dec.1999.

58 Dragoo, J. L., Samimi, B., Zhu, M., Hame, S. L., Thomas, B. J., Lieberman, J. R., Hedrick, M. H., and Benhaim, P., "Tissue-engineered cartilage and bone using stem cells from human infrapatellar fat pads," J.Bone Joint Surg.Br., vol. 85, no. 5, pp. 740747, July2003.

59 Schantz, J. T., Hutmacher, D. W., Chim, H., Ng, K. W., Lim, T. C., and Teoh, S. H., "Induction of ectopic bone formation by using human periosteal cells in combination with a novel scaffold technology," Cell Transplant., vol. 11, no. 2, pp. 125-138, 2002.

60 Schimming, R. and Schmelzeisen, R., "Tissue-engineered bone for maxillary sinus augmentation," J.Oral Maxillofac.Surg., vol. 62, no. 6, pp. 724-729, June2004. 
61 Haynesworth, S. E., Goshima, J., Goldberg, V. M., and Caplan, A. I., "Characterization of cells with osteogenic potential from human marrow," Bone, vol. 13, no. 1, pp. 81-88, 1992.

62 Wang, C., Duan, Y., Markovic, B., Barbara, J., Howlett, C. R., Zhang, X., and Zreiqat, H., "Phenotypic expression of bone-related genes in osteoblasts grown on calcium phosphate ceramics with different phase compositions," Biomaterials, vol. 25, no. 13, pp. 2507-2514, June2004.

63 Kai, T., Shao-qing, G., and Geng-ting, D., "In vivo evaluation of bone marrow stromalderived osteoblasts-porous calcium phosphate ceramic composites as bone graft substitute for lumbar intervertebral spinal fusion," Spine, vol. 28, no. 15, pp. 1653-1658, Aug.2003.

64 Ohgushi, H., Miyake, J., and Tateishi, T., "Mesenchymal stem cells and bioceramics: strategies to regenerate the skeleton," Novartis.Found.Symp., vol. 249 pp. 118-127, 2003

65 Henkel, K. O., Gerber, T., Dorfling, P., Hartel, J., Jonas, L., Gundlach, K. K., and Bienengraber, V., "[Stimulating regeneration of bone defects by implantation of bioceramics and autologous osteoblast transplantation]," Mund Kiefer Gesichtschir., vol. 6, no. 2, pp. 59-65, Mar.2002.

66 Cong, Z., Jianxin, W., Huaizhi, F., Bing, L., and Xingdong, Z., "Repairing segmental bone defects with living porous ceramic cylinders: an experimental study in dog femora," J.Biomed.Mater.Res., vol. 55, no. 1, pp. 28-32, Apr.2001.

67 Zreiqat, H., Evans, P., and Howlett, C. R., "Effect of surface chemical modification of bioceramic on phenotype of human bone-derived cells," J.Biomed.Mater.Res., vol. 44, no. 4, pp. 389-396, Mar.1999.

68 Quarto, R., Mastrogiacomo, M., Cancedda, R., Kutepov, S. M., Mukhachev, V., Lavroukov, A., Kon, E., and Marcacci, M., "Repair of large bone defects with the use of autologous bone marrow stromal cells," N.Engl.J.Med., vol. 344, no. 5, pp. 385-386, Feb.2001. 
69 Wilson, C. E., De Bruijn, J. D., Van Blitterswijk, C. A., Verbout, A. J., and Dhert, W. J., "Design and fabrication of standardized hydroxyapatite scaffolds with a defined macroarchitecture by rapid prototyping for bone-tissue-engineering research," J.Biomed.Mater.Res., vol. 68A, no. 1, pp. 123-132, Jan.2004.

70 Zein, I., Hutmacher, D. W., Tan, K. C., and Teoh, S. H., "Fused deposition modeling of novel scaffold architectures for tissue engineering applications," Biomaterials, vol. 23, no. 4, pp. 1169-1185, Feb.2002.

71 Gao, T. J., Kousinioris, N. A., Wozney, J. M., Winn, S., and Uludag, H., "Synthetic thermoreversible polymers are compatible with osteoinductive activity of recombinant human bone morphogenetic protein 2," Tissue Eng, vol. 8, no. 3, pp. 429-440, July2002.

72 Urist, M. R., "Bone: formation by autoinduction," Science, vol. 150, no. 698, pp. 893899, Nov.1965

73 Martin, I., Muraglia, A., Campanile, G., Cancedda, R., and Quarto, R., "Fibroblast growth factor-2 supports ex vivo expansion and maintenance of osteogenic precursors from human bone marrow," Endocrinology, vol. 138, no. 10, pp. 4456-4462, Oct.1997.

74 Terheyden, H., Menzel, C., Wang, H., Springer, I. N., Rueger, D. R., and Acil, Y., "Prefabrication of vascularized bone grafts using recombinant human osteogenic protein-1--part 3: dosage of rhOP-1, the use of external and internal scaffolds," Int.J.Oral Maxillofac.Surg., vol. 33, no. 2, pp. 164-172, Mar.2004.

75 Gao, T. J., Kousinioris, N. A., Wozney, J. M., Winn, S., and Uludag, H., "Synthetic thermoreversible polymers are compatible with osteoinductive activity of recombinant human bone morphogenetic protein 2," Tissue Eng, vol. 8, no. 3, pp. 429-440, July2002.

76 Obiechina, A. E., Ogunlade, S. O., Fasola, A. O., and Arotiba, J. T., "Mandibular segmental reconstruction with iliac crest," West Afr.J.Med., vol. 22, no. 1, pp. 46-49, Jan.2003. 
77 Ozawa, C. R., Banfi, A., Glazer, N. L., Thurston, G., Springer, M. L., Kraft, P. E., McDonald, D. M., and Blau, H. M., "Microenvironmental VEGF concentration, not total dose, determines a threshold between normal and aberrant angiogenesis," J.Clin.Invest, vol. 113, no. 4, pp. 516-527, Feb.2004.

78 Tanaka, Y., Sung, K. C., Tsutsumi, A., Ohba, S., Ueda, K., and Morrison, W. A., "Tissue engineering skin flaps: which vascular carrier, arteriovenous shunt loop or arteriovenous bundle, has more potential for angiogenesis and tissue generation?," Plast.Reconstr.Surg., vol. 112, no. 6, pp. 1636-1644, Nov.2003.

79 Cronin, K. J., Messina, A., Knight, K. R., Cooper-White, J. J., Stevens, G. W., Penington, A. J., and Morrison, W. A., "New murine model of spontaneous autologous tissue engineering, combining an arteriovenous pedicle with matrix materials," Plast.Reconstr.Surg., vol. 113, no. 1, pp. 260-269, Jan.2004.

80 Warnke, P. H., Springer, I. N., Wiltfang, J., Acil, Y., Eufinger, H., Wehmoller, M., Russo, P. A., Bolte, H., Sherry, E., Behrens, E., and Terheyden, H., "Growth and transplantation of a custom vascularised bone graft in a man," Lancet, vol. 364, no. 9436, pp. 766-770, Aug.2004.

81 Jaquiery, C., Rohner, D., Kunz, C., Bucher, P., Peters, F., Schenk, R. K., and Hammer, B., "Reconstruction of maxillary and mandibular defects using prefabricated microvascular fibular grafts and osseointegrated dental implants - a prospective study," Clin.Oral Implants.Res., vol. 15, no. 5, pp. 598-606, Oct.2004. 